02

\title{
Обертонное комбинационное рассеяние света в монокристаллах танталата лития
}

\author{
() С.Д. Абдурахмонов ${ }^{1}$, В.С. Горелик ${ }^{1,2, \text { Ф }}$ \\ ${ }^{1}$ Физический институт им. П.Н. Лебедева РАН, \\ 119991 Москва, Россия \\ ${ }^{2}$ МГТУ им. Н.Э. Баумана, \\ 105005 Москва, Россия \\ I e-mail: gorelik@sci.lebedev.ru \\ Поступила в редакцию 30.05.2019 г. \\ В окончательной редакции 30.05.2019 г. \\ Принята к публикации 04.06.2019 г.
}

В спектре комбинационного рассеяния света монокристаллов танталата лития обнаружены обертонные полосы в спектральном диапазоне $1300-1920 \mathrm{~cm}^{-1}$. Для регистрации спектров комбинационного рассеяния была использована $180^{\circ}$-геометрия рассеяния. В различных образцах интенсивность обертонных переходов изменялась и в некоторых случаях оказалась сравнимой с интенсивностью комбинационного рассеяния на фундаментальных модах монокристалла танталата лития.

Ключевые слова: комбинационное рассеяние, обертон, танталат лития, оптические моды, спектр.

DOI: $10.21883 /$ OS.2019.10.48352.168-19

\section{Введение}

Танталат лития $\left(\mathrm{LiTaO}_{3}\right)$ представляет собой одноосный нелинейно-оптический сегнетоэлектрический кристалл. В этом кристалле обнаруживается интенсивное комбинационное рассеяние света на полярных модах кристаллической решетки. Танталат лития является потенциальным материалом для пьезоэлектрических, электрооптических и нелинейно-оптических применений $[1,2]$. Его высокие нелинейные оптические, электрооптические, пьезоэлектрические коэффициенты используются для различных приложений. Динамика решетки танталата лития $\left(\mathrm{LiTaO}_{3}\right)$ была объектом многочисленных исследований с использованием спектроскопии комбинационного рассеяния (КР) и инфракрасного (ИК) поглощения [3-5]. В спектрах КР танталата лития обнаруживаются комбинационные спутники, соответствующие рассеянию на поперечных (TO) и продольных (LO) полярных модах с возбуждением TO- и LO-фононов $[6,7]$. Танталат лития характеризуется большой спонтанной поляризацией $\left(50 \mu \mathrm{C} / \mathrm{cm}^{2}[8]\right)$ и широко применяется в линейной и нелинейной интегральной оптике для генерации поверхностных акустических волн [9]. Этот кристалл изоструктурен с ниобатом лития и кристаллизуется в пространственной группе $R 3 c\left(C_{3 V}^{6}\right)$ ниже температуры Кюри [10]. Благодаря отсутствию центра инверсии в точечной группе симметрии $\left(C_{3 V}^{6}\right)$ и высоким значениям нелинейно-оптических коэффициентов кристаллов танталата лития имеется возможность использования этих кристаллов для генерации оптических гармоник.

В последнее время кристалл танталата лития интенсивно изучался методом спектроскопии спонтанного
КР [11-14]. При этом была получена информация только о фундаментальных оптических модах, соответствующая спектру КР первого порядка. В настоящей работе ставилась задача сравнения спектров КР монокристаллов танталата лития как в области фундаментальных мод, так и в области их обертонов, соответствующих спектру КР второго порядка в диапазоне $50-2000 \mathrm{~cm}^{-1}$.

\section{Методика эксперимента}

На рис. 1 представлена схема экспериментальной установки для регистрации спектров КР. Источником излучения служил лазер 1 с длиной волны $\lambda=785 \mathrm{~nm}$ и средней мощностью $200 \mathrm{~mW}$. Излучение лазера вводилось в световод 2 и зонд 3. Линза 5 применялась для фокусировки излучения на образце 6 , представляющем собой ориентированный монокристалл танталата лития. Сигнал КР, возникающий в образце, попадал на второй световод 8 и фильтровался в рефокусаторе 9 с помощью фотонного кристалла 11, отражающего возбуждающее излучение $(785 \mathrm{~nm})$ и пропускающего излучение КР. Далее сигнал КР попадал на вход миниспектрометра 13 с многоэлементным приемником. В качестве устройства цифровой обработки и накопления спектров КР использовался компьютер 14. Спектральное разрешение при записи спектров КР составляло $1 \mathrm{~cm}^{-1}$. Используемый волоконно-оптический метод регистрации спектров КР позволил регистрировать спектры КР монокристаллов танталата лития при разных геометриях съемки с небольшими экспозициями (10-100s) в широком спектральном диапазоне. 

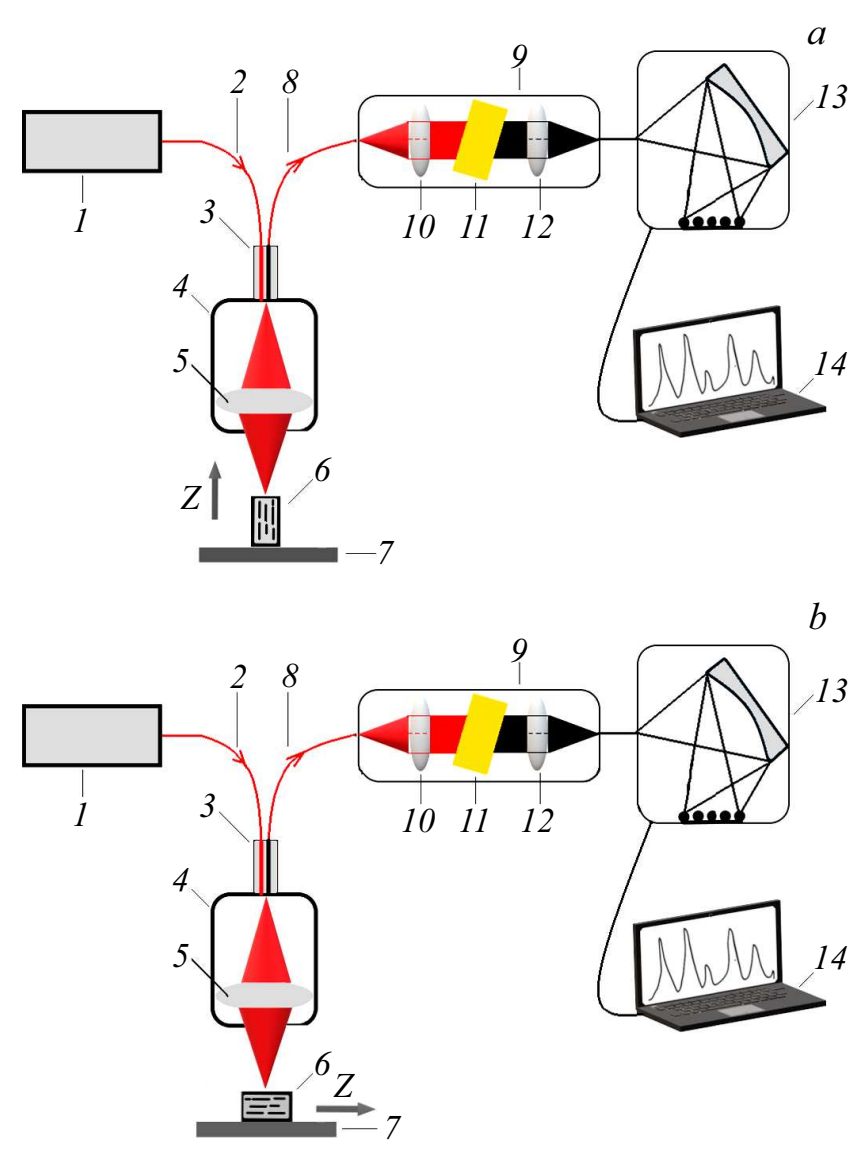

Рис. 1. Схема миниспектрометра с использованием волоконно-оптического возбуждения спектров КР: 1 - лазер, 2 - световод, 3 - зонд, 4 - корпус, 5 - линза, 6 - образец, 7 - подложка, 8 - световод, 9 - фокусатор, 10 - линза, 11 - фотонный кристалл, 12 - линза, 13 - миниспектрометр, 14 - компьютер; (a) схема для регистрации спектров КР монокристаллов при геометрии рассеяния $Z(X X ; Y Y ; Z Y) \bar{Z}$; (b) схема для регистрации спектров КР монокристаллов при геометрии рассеяния $X(Z Z ; Z Y) \bar{X}$.

\section{Результаты и их обсуждение}

На рис. 2 и 3 показаны спектры КР монокристаллов танталата лития, зарегистрированные при $180^{\circ}$ геометрии рассеяния (рассеяние „назад“), соответствующей установкам: (рис. 2, $a, b)$ и (рис. $3, a, b)$. В спектрах КР монокристаллов танталата лития (рис. 2 и 3) согласно правилам отбора проявляются поперечные (ТО) и продольные $(\mathrm{LO})$ полярные колебания $A_{1}$ - и $E$-типов. Как видно из рис. 2 и 3, спектры КР монокристаллов танталата лития состоят из большого числа узких полос. Судя по приведенным спектрограммам (рис. 2, $a, b$ ), при геометрии рассеяния возбуждаются продольные оптические фононы типа $A_{1}(\mathrm{LO})$. Обнаружено, что в спектре исследованных монокристаллов танталата лития присутствуют (рис. 2, $b$ и $3, b$ ) интенсивные обертонные полосы в спектральном диапазоне $1300-1920 \mathrm{~cm}^{-1}$. Как правило, в спектрах КР обертонные и составные полосы, классифицируемые как КР второго порядка, имеют интенсивность, на два-три порядка меньшую интенсивности соответствующего спектра КР первого порядка [15-17]. В данном случае оказалось, что при геометрии рассеяния „назад“ в спектре КР второго порядка проявляются линии, интенсивность которых сравнима или даже превышает интенсивность линий КР первого порядка (рис. 2,b). При этом обнаруживаются резкие пики, близкие по частоте к обертонным переходам с границы зоны Бриллюэна, а также обертонные переходы с центра зоны Бриллюэна. Возрастание интенсивности КР для обертонов в данном случае можно объяснить как следствие формирования связанных состояний фононов с учетом высокой плотности фононных состояний в критических точках на границе зоны Бриллюэна. В случае геометрии рассеяния в спектре КР (рис. 3, $a, b$ ) проявляются фундаментальные полосы типа $E$, а также интенсивные резкие обертонные линии, соответствующие спектру КР второго порядка. Как видно из рис. 3, $b$, при геометрии рассеяния интенсивность обертонных переходов оказывается сравнимой с интенсивностью КР
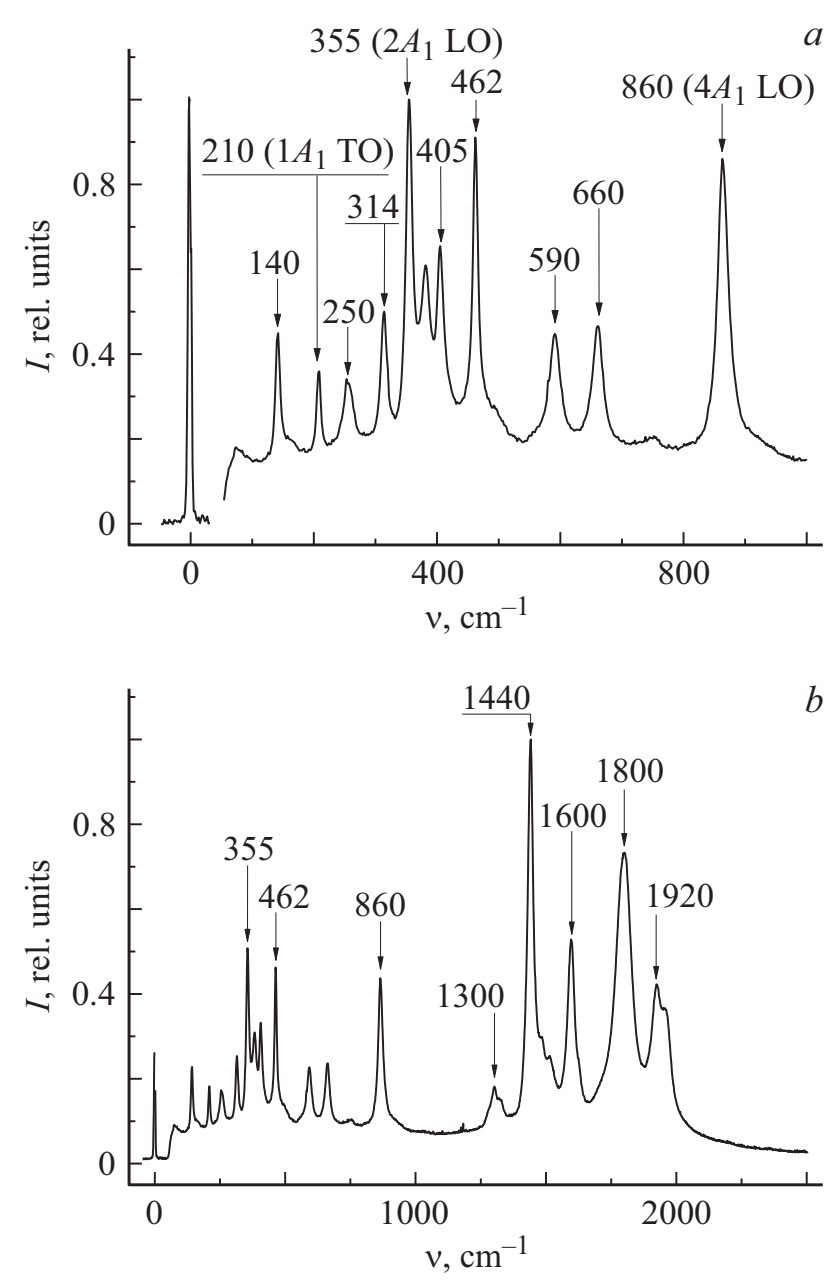

Рис. 2. Вид спектров КР в монокристаллах танталата лития при $180^{\circ}$-геометрии рассеяния с использованием волоконно-оптического возбуждения (рис. 1, $a$ ) (геометрия $Z(X X ; Y Y ; Z Y) \bar{Z})$. 

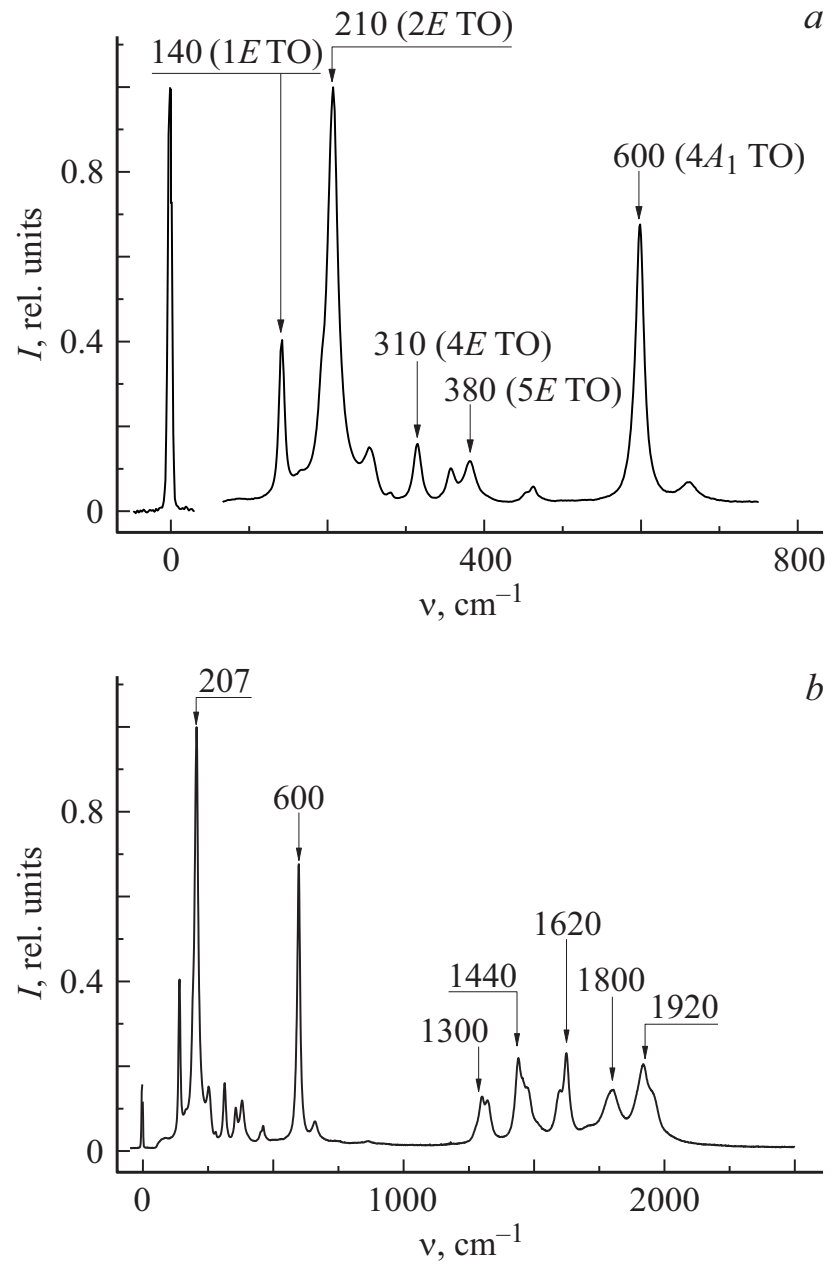

Рис. 3. Вид спектров КР в монокристаллах танталата лития при $180^{\circ}$-геометрии рассеяния с использованием волоконнооптического возбуждения (рис. $1, b)$ (геометрия $X(Z Z ; Z Y) \bar{X})$.

на фундаментальных модах монокристалла танталата лития. Аналогичный эффект возрастания интенсивности обертонных переходов обнаруживается для геометрии рассеяния, соответствующей возбуждению продольных полярных мод типа $A_{1}$ (LO), а также фундаментальных колебаний типа $E(\mathrm{TO})$. При этом частоты в спектре КР интенсивных обертонных переходов оказываются близкими для обеих обсуждаемых геометрий рассеяния „назад“. Анализ дисперсионных кривых и плотности фононных состояний в кристаллах танталата лития был выполнен в работе [18]. При этом были рассчитаны частоты фононов, соответствующих критическим точкам зоны Бриллюэна На рис. 4 проведено сопоставление спектров КР второго порядка монокристаллов танталата лития в области обертонных переходов с плотностью двухфононных состояний, рассчитанной в соответствии с работой [18]. Как видно из этих рисунков, значения частот полос в спектре КР второго порядка не совпадают с точными значениями обертонных частот фононов критических точек, а попадают в запрещенную зону между дисперсионными ветвями акустических и оптических фононов. Под действием интенсивного лазерного излучения на первом этапе происходит возбуждение оптической моды вблизи центра зоны Бриллюэна. В результате фононной релаксации внутри монокристалла происходит возбуждение фононных состояний в граничных точках зоны Бриллюэна, соответствующих взаимно противоположным направлениям волновых векторов: $\mathbf{k}_{1}=-\mathbf{k}_{2}$. Такой процесс можно интерпретировать как образование связанных состояний фононов (бифононов), соответствующих граничным точкам зоны Бриллюэна, с противоположными направлениями волновых векторов. В связи с этим в спектре КР обнаруживаются интенсивные резкие пики в области обертонных частот фононов границы зоны Бриллюэна (рис. 3 и 4). В связи с этим мы полагаем, что, с учетом эффектов ангармонизма и высокой плотности фононных состояний вблизи критических точек формируются связанные состояния пар фононов, относящихся к зеркально симметричным точкам зоны Бриллюэна. При этом волновой вектор бифонона (связанного состояния двух фононов) оказывается близким к нулю. Соответственно бифононы разрешены для на-
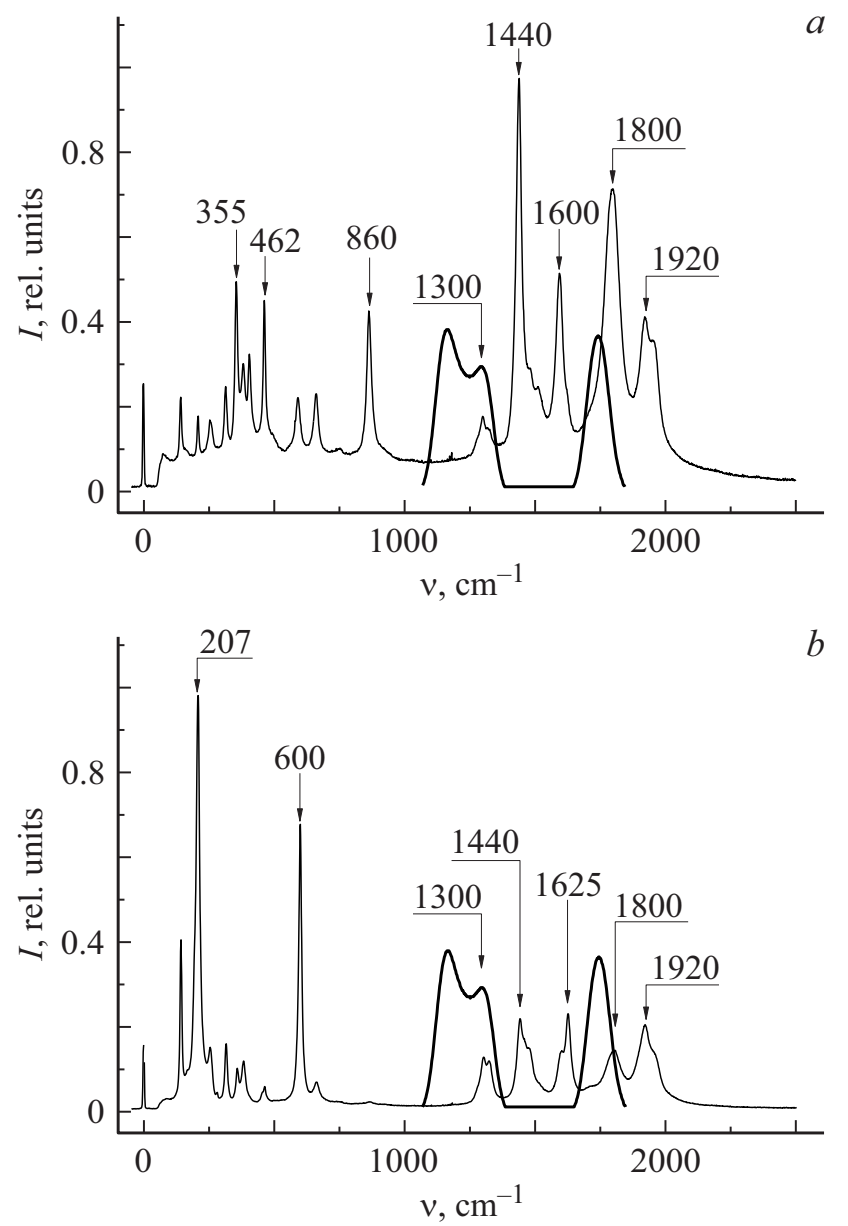

Рис. 4. Спектры КР второго порядка монокристаллов танталата лития (тонкие кривые) при геометрии рассеяния $Z(X X ; Y Y ; X Y) \bar{Z}(a)$ и $X(Z Z ; Z Y) \bar{X}(b)$ в сравнении с плотностью двухфононных состояний [18] (жирная кривая). 
блюдения в спектре КР и их интенсивность оказывается аномально высокой.

\section{Заключение}

Таким образом, в настоящей работе представлены результаты исследований спектров КР первого и второго порядков в монокристаллах танталата лития. При использовании $180^{\circ}$-геометрии рассеяния (рассеяние „назад“) обнаружено, что в спектре КР второго порядка проявляются линии, интенсивность которых сравнима или превышает интенсивность линий КР первого порядка. Наблюдаемые резкие интенсивные линии спектра КР второго порядка соответствуют обертонным переходам из центра, а также с границы зоны Бриллюэна. При этом в кристалле проявляются связанные состояния фононов - бифононы, волновой вектор которых находится вблизи центра зоны Бриллюэна. Образовавшиеся связанные состояния фононов имеют квазиимпульс, близкий к нулю $(k \sim 0)$, и обнаруживаются в спектре КР в виде резких, интенсивных пиков.

\section{Конфликт интересов}

Авторы заявляют, что у них нет конфликта интересов.

\section{Финансирование работы}

Работа выполнена за счет Российского научного фонда (проект № 19-12-00242).

\section{Список литературы}

[1] Imbrock J., Wevering S., Buse K., Kratzig E. // J. Opt. Soc. Am. B. 1999. V. 16. N 9. P. 1392.

[2] Hatanaka T., Nakamura K., Taniuchi T., Ito H., Furukawa Y., Kitamura K. // Opt. Lett. 2000. V. 25. N 9. P. 651.

[3] Kaminow I.P., Johnston W.D. // Phys. Rev. 1967. V. 160. N 9. P. 519.

[4] Penna A.F., Chaves A., Andrade P.da R., Porto S.P.S. // Phys. Rev. B. 1976. V. 13. N 11. P. 4907.

[5] Constantine R. // Phys. Rev. B. 1988. V. 38. N 14. P. 10007.

[6] Tomeno I., Matsumura S. // Phys. Rev. B. 1988. V. 38. N 1. P. 606.

[7] Hushur A., Gvasaliya S., Roessli B., Lushnikov S., Kojima S. // Phys. Rev. B. 2007. V. 76. N 6. P. 064104.

[8] Rabe K.M., Ahn C.H., Triscone J.-M. Physics of Ferroelectrics, a Modern Perspective. Topics in Applied Physics. BerlinHeidelberg: Springer-Verlag, 2007. 388 p.

[9] Xu Y. Ferroelectric Materials and their Applications. Amsterdam: Elsevier, North Holland, 1991. 406 p.

[10] Sanna S., Neufeld S., Rüsing M., Berth G., Zrenner A., Schmidt W.G. // Phys. Rev. B. 2015. V. 91. N 6. P. 224302.

[11] Johnston W.D. Jr., Kaminov J.P. // Phys. Rev. 1968. V. 168. N 3. P. 1045.

[12] Горелик В.С. // Известия РАН. Серия. Физ. 1985. Т. 49. № 2. C. 282; Gorelik V.S. // Bull. Russ. Acad. Sci.: Physics. 1985. V. 49. N 2. P. 282.
[13] Горелик В.С., Свербиль П.П., Водчии А.И., Войнов Ю.П. // Известия РАН. Сер. Физ. 2018. Т. 82. № 3. С. 299; Gorelik V.S., Sverbil P.P., Vodchits A.I., Voinov Yu. P. // Bull. Russ. Acad. Sci.: Physics. 2018. V. 82. N 3. P. 257.

[14] Gorelik V.S., Tochilin S.D., Sushchinsky M.M. // J. Mol. Struct. 1986. V. 143. P. 83.

[15] Shuo L., Zhanlong L., Shenghan W., Shuqin G., Chenglin S., Zuowei L. // Mater. Res. Bull. 2015. V. 72. P. 1.

[16] Liu T., Xu S., Li Z., Wang M., Sun C. // Spectrochim. Acta. A. 2014. V. 131. P. 153.

[17] Eric J.H., Yuan Y., Lucas K., Wei C., Shiang F., Mario B., Efthimios K. // ACS Nano. 2016. V. 10. N 2. P. 2803.

[18] Friedrich M., Schindlmayr A., Schmidt W.G., Sanna S. // Phys. Stat. Sol. B. 2016. V. 253. N 4. P. 683. 